技術

資料

Technical

Information

\section{What is the Best Propeller for Zero Emission Ultimate Ship (ZEUS) ? ${ }^{*}$}

Noriyuki Sasaki*

\begin{abstract}
The concept of Zero Emission Ultimate Ship (ZEUS) concept is an idea of promising future vessels which utilize several key technologies such as a hybrid diesel electric propulsion system, a reaction pod and an extremely wide twin skeg hull form.

This paper mainly deals with the reaction pod propulsion system and propeller design that is well adapted to this new concept.
\end{abstract}

\section{INTRODUCTION}

It is very obvious that electric propulsion(s) will be the final solution for a main engine of a future vessel. On the other hand, a petroleum-electric hybrid most commonly uses internal combustion engines and electric batteries to power electric motor for cars and other small transportation systems. The advantage of a hybrid car is of course performance and the key to a hybrid car is that engine can be much smaller than conventional car engine by applying assisting system of the electric motor and battery. The engine size can be minimized and is sized closer to the average power requirement than the peak power. Moreover the electric motor on a hybrid car is very sophisticated. Advanced electronics can allow it to act as a motor as well as a generator. Therefore the electric motor can slow the car down and return energy to the batteries when it is acting as a generator. At the moment the same system is hardly installed on a sea born vessel because the vessel is always traveling without stopping motion. However hybrid engine system such as diesel electric will be a good solution for reducing $\mathrm{CO}_{2}$ emission by creating a new concept hull form utilizing it's strong points.

Zero Emission Ultimate Ship (ZEUS) concept is idea of

* Received February16,2011

** National Maritime Research Institute(NMRI), Mitaka, Tokyo, Japan promising future vessels. The key technologies of this concept can be divided into two parts, i.e., a new engine technology and hull form design technology including propulsion system. In this paper, latter hull form design technology, mainly the propulsion system and a propeller design, will be discussed.

\section{ZEUS PROJECT}

The total amount of $\mathrm{CO}_{2}$ emission from ships is estimated as around $3 \%$ of emission from the entire globe and the figure is corresponding to emission from the country Germany. UNFCCC (United Nations Framework Convention on Climate Change) has requested IMO to kick around the reduction of GHG (Green House Gas) emitted from ocean going vessels. In order to contribute to this push, NMRI has started ZEUS project from the beginning of 2009 and mile stones were decided as follows;

ZEUS 1: Reduction of $50 \%$ by Hull Form Design, Reaction Pod and Boundary Layer Control

ZEUS 2: $\quad$ Reduction of $80 \%$ by Hybrid Engine, Solar Energy and Electric Supply System addition to ZEUS1

ZEUS 3: Reduction of $100 \%$ by Fuel Cell addition to ZEUS 2

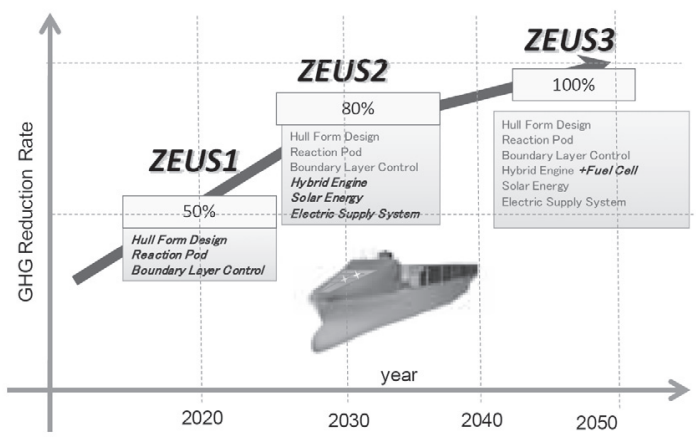

Figure 1 Road map of GHG reduction rate by ZEUS projects 
As shown in Figure1, until 2020 Hydrodynamic technology will play a main role and after ZEUS 1 it will be required to introduce Hybrid Engine technology. At the final goal, we expect Fuel Cell as a energy supply system of ocean going vessels.

\subsection{ZEUS 1 Concept}

There are three ways to minimize EEDI given by equation (1).

$$
E E D I=\frac{\mathrm{CO}_{2}(g)}{\text { Capacity } \cdot V_{S}}
$$

The first way is to increase capacity and that is achieved by twin skeg hull form under the limitations of ship length and draft. The second way is to reduce $\mathrm{CO}_{2}$ by increasing propulsive efficiency by applying reaction pod and boundary layer control. The last way is to increase ship speed without any additional power. There are two countermeasures for this. One is to increase efficiency of cargo handling/loading and another one is to have better sea keeping ability.

ZEUS concept is the most efficient idea to reduce EEDI. The first phase of ZEUS project is named " ZEUS 1" and the most realistic technologies will be used in order to achieve $50 \%$ reduction of $\mathrm{CO}_{2}$ emission by 2030 . The key technologies under investigating are twin skeg hull form with wide beam, reaction pods concept and boundary layer suction control.

Table 1 Key Technologies of ZEUS 1

\begin{tabular}{|c|c|c|}
\hline Key technologies & objective & Target values \\
\hline $\begin{array}{l}\text { Twin Skeg hull with } \\
\text { wide beam }\end{array}$ & $\begin{array}{l}\text { Increase } \\
\text { weight } \\
\text { propulsive } \\
\text { efficiency }\end{array}$ & $\begin{array}{l}\text { Reduce } \\
18 \% \\
\text { Satisfy IMO } \\
\text { standard A } 751^{*}\end{array}$ \\
\hline Reaction pod & $\begin{array}{l}\text { Increase propulsive } \\
\text { efficiency }\end{array}$ & \\
\hline Step & $\begin{array}{l}\text { Reduce added wave } \\
\text { resistance }\end{array}$ & $\begin{array}{l}10 \% \text { of added } \\
\text { wave resistance }\end{array}$ \\
\hline $\begin{array}{ll}\text { Boundary } & \text { layer } \\
\text { control(BLC) } & \end{array}$ & $\begin{array}{l}\text { Maneuvering by } \\
\text { BLC } \\
\text { Reduce viscous } \\
\text { resistance and } \\
\text { increase propulsive } \\
\text { resistance }\end{array}$ & $\begin{array}{l}\text { No helm under } \\
10 \text { deg. } \\
\text { Reduction of } \\
\text { viscous } \\
\text { resistance by } 5 \% \\
\text { Increase } \\
\text { propulsion } \\
\text { efficiency by } 2 \%\end{array}$ \\
\hline
\end{tabular}

*Resolution A751 ; IMO: INTERIM STANDARDS. FOR SHIP. MANOEUVRABILITY,

\subsubsection{Twin Skeg Hull Form with Wide Beam}

Twin skeg hull form itself is not a new idea and a few vessels of this type have been built. The main difference between ZEUS and existing twin skeg vessels is an application of podded propulsion system. By adopting podded propulsion system, design capabilities of the vessel can be much improved. The most important point is that ZEUS requires no shafts and engine room inside of both skegs. This means that the designer can optimize stern part only taking the optimum propulsive efficiency into account.

By increasing beam until the transportation efficiency reaches the maximum, the payload (capacity) can be increased without sizing up of her length and draft. The maneuverability is not a big concern because the twin skeg hull form has a superior course keeping ability from the very start. In order to estimate the performance of twin skeg hull form, empirical powering method was introduced. The main functions of the program are as follows:

\section{Prediction of wetted surface area}

Wetted surface area of a twin skeg hull form is larger than that of a conventional single screw ship because the tunnel part increases the girth length. The estimation was made based on next empirical formula.

$S_{W}=S_{W}(s g l)+1.1 \cdot L_{S K E G} \cdot H_{S K E G}$
$S_{W}(s g l)=1.005 \cdot L_{P P}\left(1.81 \cdot d+C_{B} \cdot B\right)$

\section{Prediction of form factor}

Form factor of twin skeg hull form can be predicted by data base which was plotted based on stern fullness such as

$$
p=\gamma_{A} \cdot C_{M} /\left(\frac{L}{B} \cdot\left(B / d * C_{B}\right)^{0.5}\right)
$$

Where

$$
\gamma_{A}=\frac{1}{(L / B) \cdot\left(1-C_{P A}\right)}
$$

By using the above parameters, form factor $K$ of twin skeg hull can be estimated by following equations;

$$
\begin{aligned}
& K=2.25 p^{\prime}+0.05+\Delta K_{\varphi} \\
& \Delta K_{\varphi}=0.223 \ln (\varphi)-0.518 \quad \varphi \geq 10 \mathrm{deg}
\end{aligned}
$$

Where, $p$ ' is given by equation (4) substituting $\mathrm{B}$ by $(\mathrm{B} / 2)$ and $\varphi$ is inclining angle of tunnel between skegs.

CFD can be utilized to predict form factor however, it will 
be safe to combine data base and CFD calculations. CFD was used to predict the effect of small deviations from parent model or local deformation of stern form.

\section{Prediction of wave making resistance}

The stem of twin skeg hull form of ZEUS is very similar to conventional vessel except her wide beam and slender body. Therefore the wave resistance can be estimated easily based on existing data base or theoretical calculations. In our project, Ranking source method was used for prediction at final design phase as shown in Figure.2. At initial design phase, simple prediction method can be utilized based on empirical formulae such as ;

$$
\begin{aligned}
& r_{W}=f\left(\gamma_{E}, F_{N}\right) \\
& \gamma_{E}=\frac{1}{(L / B) \cdot\left(1-C_{P F}\right)}
\end{aligned}
$$

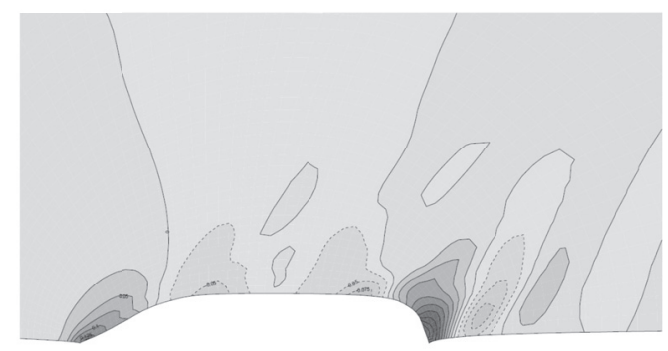

Figure 2 Wave contour of ZEUS container ship calculated by Rankin Source Method

\section{Prediction of thrust deduction factor}

Thrust deduction factor is interaction term between a podded propulsor and a ship stern. This factor is very sensitive to the gradient of water lines in front of a propeller. Therefore thrust deduction factor of ZEUS hull form is superior to conventional hull form because there is no limitations of skeg shapes affected by propeller shafts and engine spaces. Moreover the skeg shapes can be designed so as to guide the rotational flows originated from the stern. Thrust deduction factor of twin skeg hull can be predicted by following equation;

$$
(1-t)=-12.75 p^{\prime 2}+0.605 p^{\prime}+0.86
$$

\section{Prediction of wake fraction}

Similar method can be used to predict wake fraction as we used to predict thrust deduction factor. The difference from a single screw ship is non symmetrical wake.

Therefore we need to consider two equations for different rotational direction.

$$
\begin{aligned}
& (1-w)_{I N}=(1-w)_{M E A N}-\frac{1}{2} \Delta w \\
& (1-w)_{O U T}=(1-w)_{M E A N}+\frac{1}{2} \Delta w
\end{aligned}
$$

Where,

$$
\begin{aligned}
& (1-w)_{\text {MEAN }}=-2.619 p^{\prime}+0.826 \\
& \Delta w=0.1062 \ln \left(p^{\prime}\right)+0.5
\end{aligned}
$$

As mentioned the above, wake fraction contains not only viscous wake and potential wake but also rotational component. Therefore we need a special consideration for wake scaling. The wake fraction $w_{M}$ of a twin skeg ship with reaction pods can be described as follows;

$$
w_{M}=w_{H F}+w_{H P}+w_{R}
$$

Where, $w_{H F}, w_{H P}, w_{R}$ are frictional wake, potential wake and rotational wake respectively. The wake scaling procedure will be discussed in section 6.2.1.

\section{$\underline{\text { Relative rotative efficiency }}$}

There is no specific point for twin skeg hull form and reaction pod from relative rotative efficiency aspect. Therefore conventional data base can be used.

By applying the above idea, the program can simulate the powering performance of twin skeg hull form and it can find the optimum point where the minimum EEDI exists.

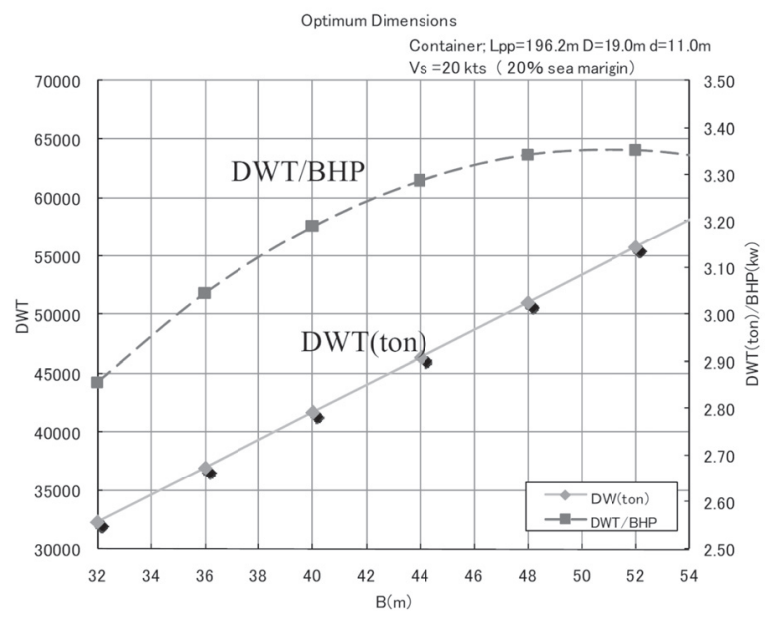

Figure 3 Optimum beam(B) simulated by NMRI powering program "HOPE" 
Figure 3 shows an example of prediction of twin skeg container ship based on the above simulation program. The optimum point can be easily predicted as shown in the figure.

\subsubsection{Reaction Pods}

Reaction pod is the name of new concept and it means the optimum pod arrangement for the twin skeg hull form. The typical ship wake of twin skeg hull form is shown in Figure.3. Two remarkable characteristics can be seen in the figure, one is a similar wake pattern to a conventional single screw ship outside of a skeg and another one is up going flow inside of a skeg as shown. A reaction pod is located in the rather inside of center line of skeg in order to obtain both counter flow and viscous flow as shown in Figure.3. The left hand side of propeller disc exists behind a skeg center line and right hand side of propeller disc exists in the up going main flow in the tunnel.
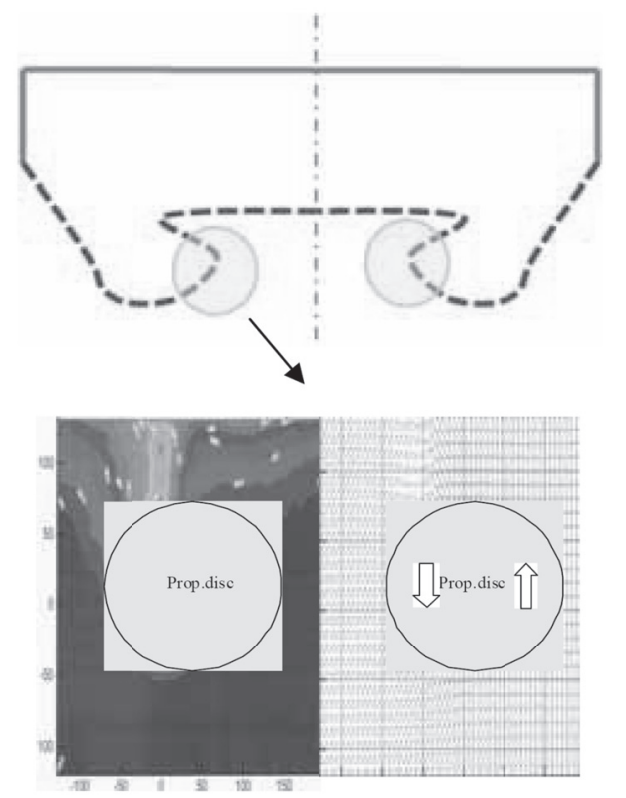

Figure 4 Axial wake(left) and Tangential wake(right)

\section{DESIGN SHIP}

Two vessels, a medium size container ship and over panama type bulk carrier are studied and designed based on ZEUS concept. Table 2 shows the principal dimensions of a container ship.

In this paper, only a container ship will be discussed because there are no remarkable differences between two vessels from the aspect of technical points which we will exposit.
Table 2 Designed Vessel

\begin{tabular}{|c|c|}
\hline Carrier & NMRI Line \\
\hline$L p p(\mathrm{~m})$ & 196.2 \\
\hline$B(\mathrm{~m})$ & 42.8 \\
\hline$D(\mathrm{~m})$ & 19 \\
\hline$d(\mathrm{~m})$ & 11 \\
\hline$D W T($ ton $)$ & 49000 \\
\hline$T E U$ & 4000 \\
\hline$V s($ kts $)$ & 20.0 \\
\hline$M / E$ & Podded Propulsion \\
\hline
\end{tabular}

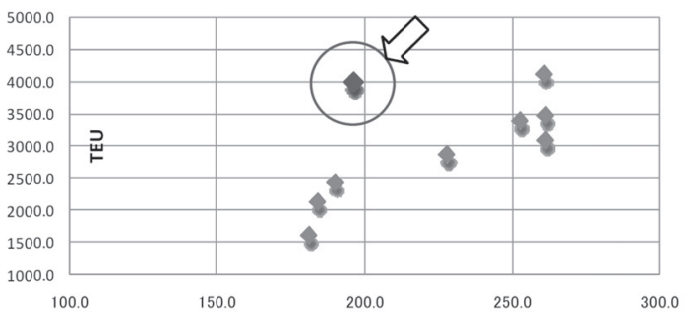

Figure 5 Capacity of a Container Ship of ZEUS 1
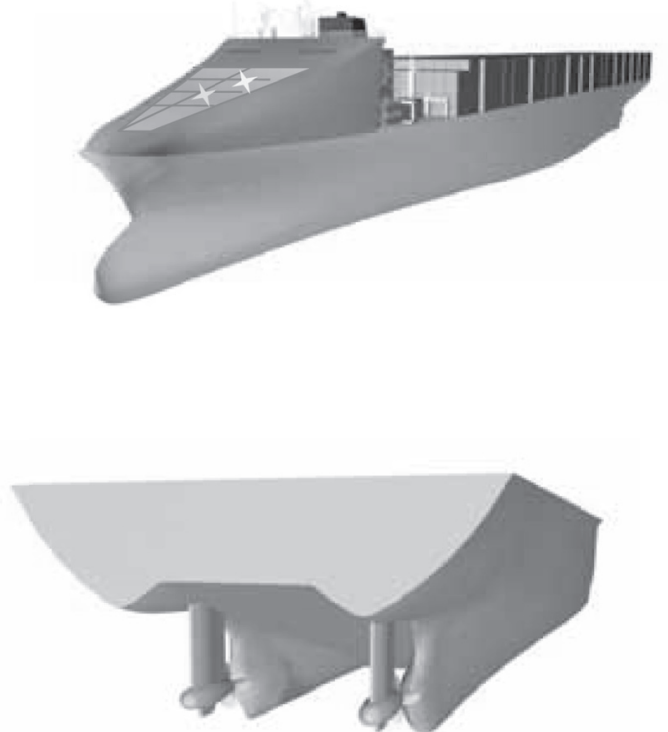

Figure 6 Image of ZEUS 1

\section{PROPULSION SYSTEM}

The propulsion system is a hybrid engine combined by diesel electric and batteries. Generators derived by diesel engines are located in the bow part apart from cargo rooms and batteries are in the skegs. Two azimuthing podded propulsors are main propulsors and principal dimensions of the podded propulsor are listed in the Table 2. Figure 6 shows the image of ZEUS concept.

\section{PROPELLER DESIGN}


It is generally recognized that the propeller design of single screw has been developed and well established already and though the wake distribution is not homogeneous, symmetrical wake can be assumed. In the case of twin screw ships, the wake is almost homogeneous and pitch distributions are decided taking the cavitation performance into account. On the contrary, the propeller design of ZEUS hull form is quite different from conventional ships because of strong tangential wake as shown in Figure 4. Therefore special treatment for propeller design, especially in pitch distribution, will be needed. It can be said that the design procedure of the propeller of ZEUS hull similar to the procedure of an aft propeller of CRP (Contra Rotating Propellers). The propeller design of an aft propeller of CRP is as follows:

Step1 : design of standard propeller in totally uniform wake

Step2: correction of pitch distributions for nonuniformity of mean axial flow

Step3: correction of pitch distributions for non uniformity of mean tangential flow

\subsection{Correction of pitch distributions for non uniformity of mean axial flow}

Pitch correction due to non uniform axial flow can be calculated by wake adopted design scheme which was presented by van Manen(1952). Pitch ratio of radius $r$ can be obtained by following equation;

$$
p(r)=p_{0}\left(\frac{1-w_{T}(r)}{1-w_{\text {MEAN }}}\right)^{0.75}
$$

Where $w_{T}(r)$ is effective wake at radius $r$ and $w_{\text {MEAN }}$ is mean effective wake and represented by following equation by using loading function $f(r)$;

$$
w_{\text {MEAN }}=\frac{\int_{c}^{1} f(r) w_{T}(r) d r}{\int_{c}^{1} f(r) d r}
$$

\subsection{Correction of pitch for non uniformity of mean} tangential flow

Pitch correction due to non uniform tangential flow can be calculated by following idea.

$$
d_{Q 1}=d_{Q 0}
$$

Where, $d_{Q 0}, d_{Q 1}$ represent blade element torque at radius $r$ without tangential flow and with tangential flow respectively. The idea is both torque should be equal to satisfy the design condition. From the blade element theory, $d_{Q 0}, d_{Q 1}$ can be represented by;

$$
\begin{aligned}
& d_{Q 0}=\frac{1}{2} \rho W_{0}^{2}\left(C_{D \min } \cos \beta_{0}+C_{L 0} \sin \beta_{0}\right) r d r \\
& d_{Q 1}=\frac{1}{2} \rho W_{1}^{2}\left(C_{D \min } \cos \beta_{1}+C_{L 1} \sin \beta_{1}\right) r d r
\end{aligned}
$$

Where, $W$ is resultant velocity of blade element and $C_{D \min }, C_{L}$ are minimum drag coefficient and lift coefficient respectively.

By solving the above equations, pitch angle with tangential flow $\psi_{1}$ can be represented by following equation using pitch angle without tangential flow $\psi_{0}$ and hydrodynamic pitch angle $\beta$.

$$
\psi=\frac{\left(\psi_{0}-\beta_{0}\right) \sin \beta_{0}}{\zeta \sin \beta_{1}}+\frac{C_{D \min }\left(\cos \beta_{0}-\zeta \cos \beta_{1}\right)}{2 \pi k \zeta \sin \beta_{1}}+\beta_{1}
$$

Where,

$$
\zeta \cong 1+\frac{V_{T}(r)+2 V_{T}(r)\left(r \Omega-u_{T}(r)\right)}{\left(r \Omega-u_{T}(r)\right)^{2}+\left(V_{X}+u_{X}(r)\right)^{2}}
$$

Where, $V_{T}$ is tangential velocity originated from ship wake and $u_{X}, u_{T}$ are axial induced velocity and tangential induced velocity respectively. Those are computed by conventional propeller design program based on lifting line( or surface) program.

According to the design procedure mentioned above and NK strength criteria for full scale, 3 bladed propellers with NACA section were designed. Figure 7 shows the photo of the model propellers and principal dimensions are listed in Table 2.

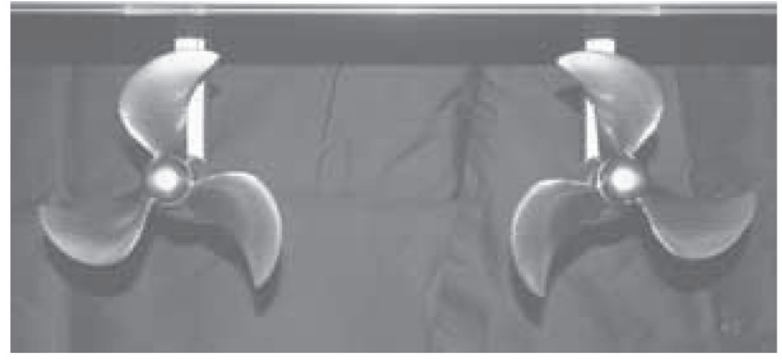

Figure 7 Photo of model propellers

\section{MODEL TEST}

It is particularly worth noting that the strong point of reaction pod system is the capability of the best location of pod propulsor taking counter rotating effect as a 
contra-rotation propeller into account. The wake pattern of twin skeg hull form based on ZEUS concept is superior to a conventional twin skeg hull because of less restriction for skeg thickness and shape. The skeg can be designed so as to increase the highest propulsive efficiency. Owing to the favorable wake patterns of ZEUS hull form as described in 2.2.2, the propulsive efficiency over $90 \%$ of the vessel is achievable goal.

\subsection{Ship model and propeller model}

Model tests was conducted with $5.418 \mathrm{~m}$ paraffin model and twin podded propulsion system at $400 \mathrm{~m}$ towing tank of National Maritime Research Institute. Table 2 shows principal dimensions of ship model and propeller model.

Table 2 Ship Model and Propeller Model

\begin{tabular}{|c|c|l|l|}
\hline \multicolumn{2}{|c|}{ Ship Model } & \multicolumn{2}{c|}{ Propeller Models } \\
\hline $\mathrm{Lpp}(\mathrm{m})$ & 5.418 & Diameter(m) & 0.226 \\
\hline $\mathrm{B}(\mathrm{m})$ & 1.182 & Pitch Ratio & 1.020 \\
\hline $\mathrm{d}(\mathrm{m})$ & 0.2955 & $\begin{array}{l}\text { Expanded } \\
\text { Area Ratio }\end{array}$ & 0.35 \\
\hline $\mathrm{CB}$ & 0.6564 & Boss Ratio & 0.18 \\
\hline LCB(\%Lpp) & 3.55 & $\begin{array}{l}\text { Number of } \\
\text { Blades }\end{array}$ & 3 \\
\hline
\end{tabular}

\subsection{Prediction method of full scale performance}

The most advantageous point to regard the pod unit as a propulsor is a fact that the scale effect on the hull wake can be treated similar to the wake for conventional ships.

Therefore existing extrapolation methods of wake fraction described in a procedure 7.5-02-03-01.4 "1978 propulsion prediction method for single screw ships" can be applied without any modification.

In the case of twin skeg hull, scale effect is slightly different from a single screw vessels because of non symmetry of wake pattern. The wake composes tangential wake and this component should be treated different way from viscous wake.

\subsubsection{Wake Scaling}

The measured wake by propulsion test based on thrust identity method can be presented as follows;

$$
w_{M}=w_{H F}+w_{H P}+w_{R}
$$

Where, $w_{H F}, w_{H P}$ are hull viscous wake and hull potential wake respectively.

$w_{R}$ is rotational component due to tangential flow. It is noted that the rudder wake is not appeared because the podded propulsor is regarded as a propulsor.

Only hull viscous wake will require scale correction in these wake components and the calculation will follow ITTC prediction method as mentioned above.

$$
\frac{w_{H F S}}{w_{H F M}}=\frac{(1+K)\left(C_{F S}+\Delta C_{F}\right)}{(1+K) C_{F M}}
$$

$K \quad:$ Form factor

$C_{F}$ : Frictional resistance coefficient

$\Delta C_{F}:$ Skin friction correction

The suffix $\mathrm{M}$ and $\mathrm{S}$ mean model and ship respectively.

Next question is how we can separate these three wake components.

Here we can expect an advantage again by using ITTC powering method concerned with podded propulsion. The potential wake component can be replaced by thrust deduction factor same as a single screw procedure. Regarding rotational component, it is recommended to conduct self propulsion tests both with clock wise and counter-clock wise propeller rotations. From the results of two propulsion tests, we can obtain $w_{R}$ as follows;

$$
w_{R}=\frac{w_{C W}-w_{C C W}}{2}
$$

\subsubsection{Pod Housing Drag Correction}

The pod housing drag including the effect of propeller action can be assumed to be

$R_{\text {FOD }}=R_{\text {BODY }}+R_{\text {STRUT }}+R_{I N T}+R_{\text {LIFT }}$

Where, $R_{B O D Y}, R_{\text {STRUT, }} R_{I N T}$ and $R_{\text {LIFT }}$ are components of the resistance associated with pod body, strut-pod, body-strut interference and component due to lift effect by propeller swirling flow respectively. By using the basic idea of form factors approach, $R_{B O D Y}$ and $R_{S T R U T}$ can be represented in the following manner;

$$
\begin{aligned}
& R_{\text {BODY }}=\left(1+k_{\text {BODY }}\right) * R_{\text {FBODY }} \\
& R_{\text {STRUT }}=\left(1+k_{\text {STRUT }}\right) * R_{\text {FSTRUT }}
\end{aligned}
$$

Interference drag, $R_{I N T}$ can be represented by the following semi-empirical formula:

$$
R_{I N T}=\frac{1}{2} * \rho * V^{2} * t^{2} * f\left(\frac{t_{R O O T}}{C_{R O O T}}\right)
$$

with

$$
f\left(\frac{t_{R O O T}}{C_{\text {ROOT }}}\right)=C_{\text {ROUND }} *\left(17 *\left(\frac{t_{R O O T}}{C_{R O O T}}\right)^{2}-0.05\right)(30)
$$


Where, $t_{R O O T}$ is maximum thickness as strut and $C_{R O O T}$ is chord length at the same section.

$C_{R O U N D}$ is correction factor for various fairing and it varies 0.6 to 1.0 .

The resistance of pod body can be presented by simple formula given by Hoerner

$$
\begin{aligned}
& R_{B O D Y}=\left(1+k_{B O D Y}\right) *\left(\frac{1}{2} * C_{F} * \rho * V^{2} * S\right) \\
& K_{B O D Y}=1.5 *\left(\frac{D}{L}\right)^{\frac{3}{2}}+7 *\left(\frac{D}{L}\right)^{3}
\end{aligned}
$$

$S:$ Wetted surface Area $\left(\mathrm{m}^{2}\right)$

$L$ : Pod length (m)

$D$ : Pod diameter (m)

The resistance of strut can be presented as the same manner and $k_{\text {STRUT }}$ is also presented by simple formula.

$$
\begin{aligned}
& R_{\text {STRUT }}=\left(1+k_{\text {STRUT }}\right) \cdot \frac{1}{2} \rho C_{F} V^{2} S \\
& k_{\text {STRUT }}=2 \delta_{S}+60 \delta_{S}^{4}
\end{aligned}
$$

Where, $\delta_{S}$ is average thickness ratio of the strut and $S$ is wetted surface area of the strut.

Following formula can be used to predict axial inflow velocity which is accelerated by a propeller.

$$
V_{\text {INFLOW }}=V_{A}\left(1+C_{T}\right)^{0.5}
$$

Where, $V_{A}$ is advance speed of propeller. $C_{T}$ is thrust coefficient defined by

$$
C_{T}=\frac{T}{\frac{1}{2} \rho V_{A}{ }^{2} A_{P}}
$$

$T$ : propeller thrust $(\mathrm{N})$

AP: propeller disc area $(\mathrm{m} 2)$

\subsection{Analysis of Model Test based on Present Methods \\ 6.3.1 Pod open water test}

Before conducting self propulsion tests, pod open water test was conducted. The results are shown in Figure 8.

The working point is $C_{T}=0.51$ and two experiments values, the pod propulsor open water efficiency and the propeller open water efficiency with the same propeller without pod.(CP MAU3), can be evaluated directory from Figure 8.

The pod open water efficiency (0.65) of model scale show considerably low compared with the propeller open water efficiency (0.76) with the same propeller because of pod housing drag. The difference of two open water efficiency is about $15 \%$ and this value is larger than a normal pod propulsor case.

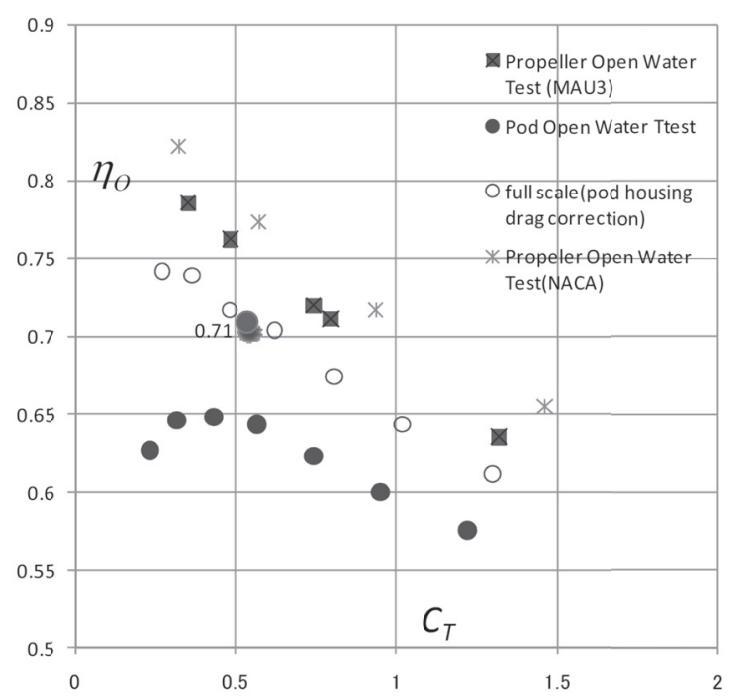

Figure 8 Result of Pod/Propeller Open Water Test

In this figure, another two remarkable points can be seen. The first point is that pod open water efficiency of full scale which is estimated by ITTC prediction method as described section 6.2.2 is 0.71 . Another point is that propeller efficiency of a designed propeller based on a normal design procedure is 0.78 and that is higher than $\mathrm{CP}(\mathrm{MAU} 3)$ by abt. $3 \%$

\subsubsection{Pod Housing Drag Correction}

Figure 9 shows the results of calculation according to $25^{\text {th }}$ ITTC pod housing drag correction method. The total resistance of calculation can be compared with model test result under the same propeller thrust condition.

If both total resistances values are close, it implies that the calculated resistance components are well predicted.

As can be seen in Figure 8 , the accuracy of ITTC method seems to be sufficient.

By assuming the frictional resistance can be corrected by ITTC method, full scale pod open water efficiency can be estimated and plotted in Figure 7. Here, the difference between pod propulsor and CP MAU 3 is $7 \%$. 

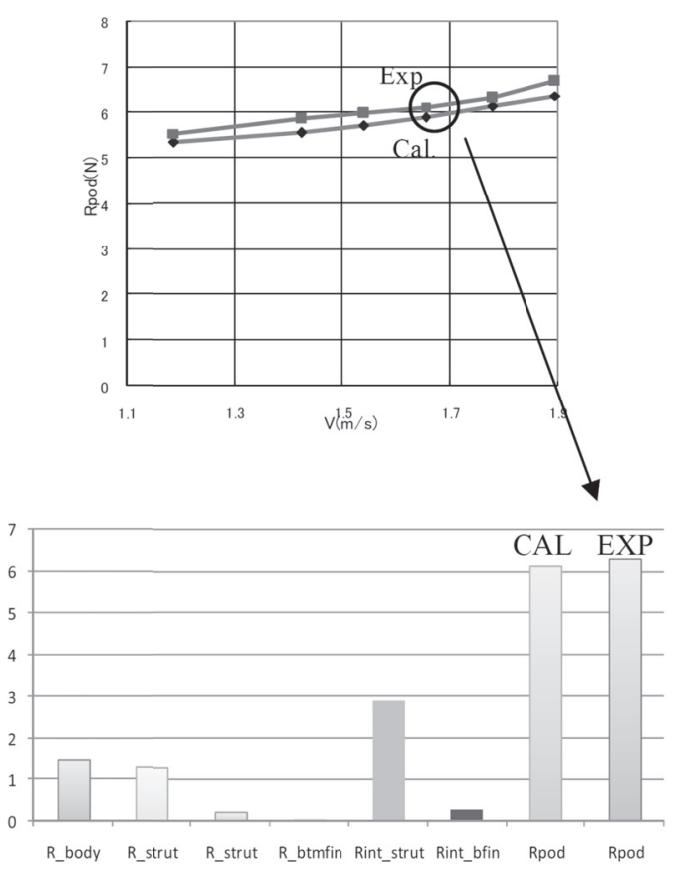

Figure 9 Pod housing drag correction according to $25^{\text {th }}$ ITTC procedure

\subsubsection{Self Propulsion Tests}

Figure 10 shows the stern arrangement of ZEUS container ship. Twin pods are located behind two skegs and both center of pod struts are shifted inside as described in section 2.1.2. The positions of pods were shifted automatically by pod traverse as shown in Figure 10 and the optimum position of the pods was investigated. Figure 11 shows the results of self propulsion tests changing the pod position with transverse direction. It is noted that the maximum hull efficiency of model scale can be obtained near $10-15 \%$ of propeller diameter off center and the hull efficiency of $123 \%$ may be a record breaking for twin screw containerships.

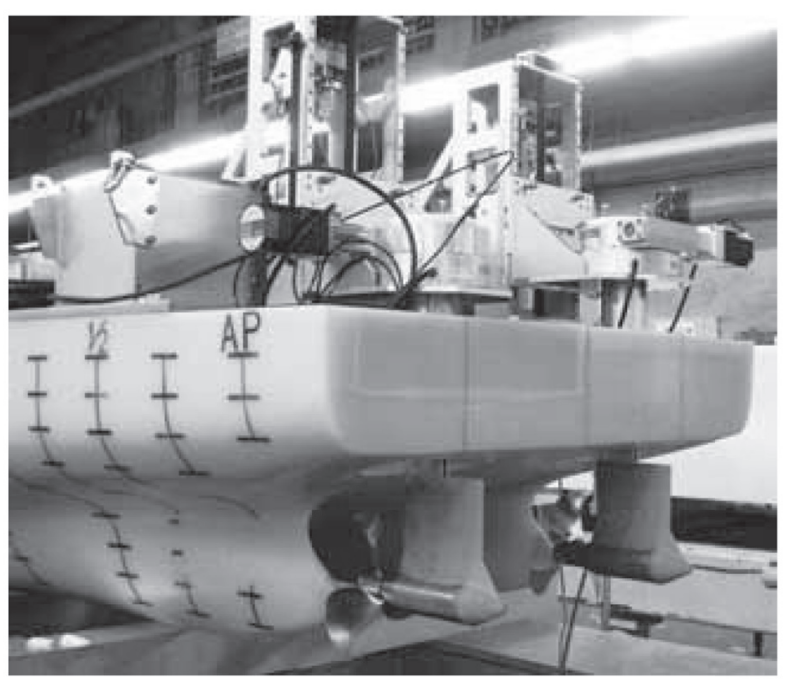

Figure 10 Twin pods traverser

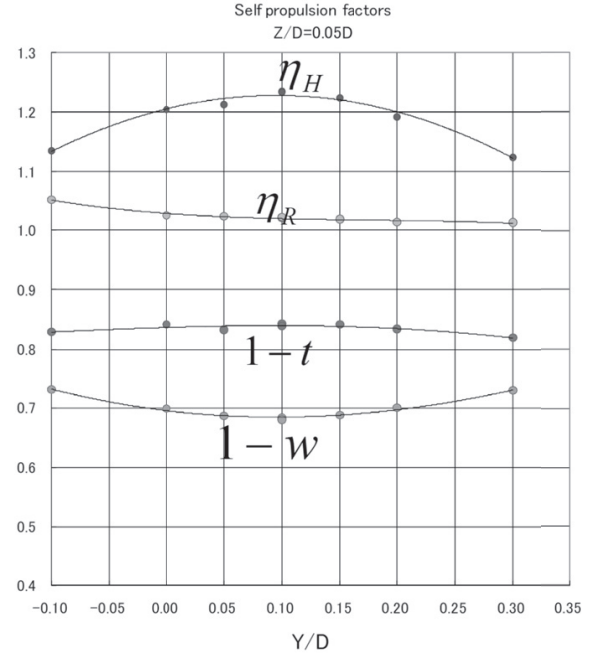

Figure 11 Pod positions and self propulsion factors

\section{Economical Study}

In order to evaluate economical efficiency of ZEUS, comparison was made based on next economical index.

$$
E . I .=\frac{\mathrm{kW}(a t 20 \mathrm{kts})}{\mathrm{TEU}}
$$

Generally speaking dead weight or container payload of conventional vessels are not clear because they claim combined data with dead weight of scantling draft and service speed of design draft. Therefore following assumptions were made.

The ship speed of scantling draft can be estimated by using the same admiral coefficient. The sea margin of all vessels is assumed $20 \%$.

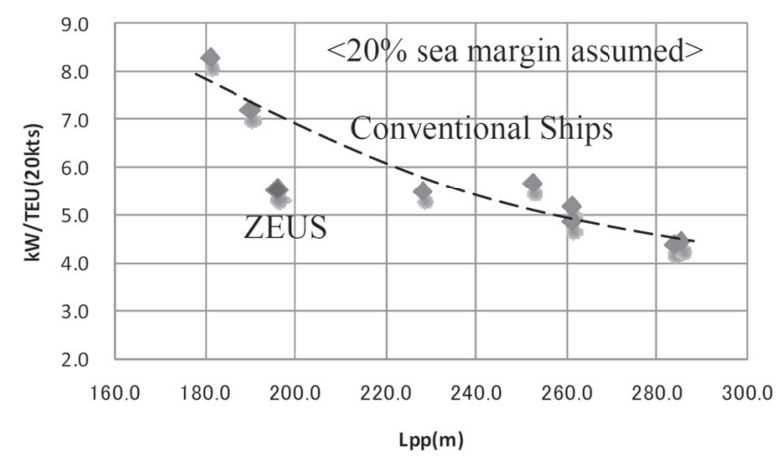

Figure 12 Required power for 1(one)TEU

The result is shown in Figure 12. It is very obvious that the index of ZEUS is better than conventional ships more than $20 \%$. 


\section{CONCLUSION}

The key technologies of Zero Emission Ultimate Ship (ZEUS) concept are reviewed from not only theoretical aspects but also experimental studies. From the studies, it is very clear that the concept of ZEUS is very promising and expansive. Main conclusions which were obtained here are as follows;

$\checkmark \quad$ By combination of a twin skeg hull form and twin pods, high propulsive efficiency more than $90 \%$ can be obtained

$\checkmark \quad$ It is very effective to adopt reaction pod concept where the pod location is off centered.

$\checkmark \quad$ The propeller design for the reaction pod is established by adopting similar design procedure as contra rotating propellers

$\checkmark \quad$ Economical Index (kW/DW) of ZEUS is better than conventional container ships more than $20 \%$ even allowing energy loss $12 \%$ of electric propulsion

\section{ACKNOWLEDGMENT}

The author would like to thank all NMRI members of ZEUS project for their dedicated efforts and hope they will co-operate to develop a next new type of vessel based on ZEUS concept.

\section{REFERENCES}

$25^{\text {th }}$ ITTC Proceedings vol.2 "Report of the Specialist Committee on Azimuthing Podded Propulsion" 2008

van Manen J.D. and Troost L. "The design of ship screws of optimum diameter for an equal velocity field" Trans. SNAME.1952 